\title{
Communication \\ A Proposed Protocol for Ordinary and Extraordinary Hygienic Maintenance in Different Implant Prosthetic Scenarios
}

\author{
Pietro Felice ${ }^{1, *}$, Angelica Bertacci ${ }^{2}$, Lorenzo Bonifazi ${ }^{1,3}$, Maryia Karaban ${ }^{1}$, Luigi Canullo ${ }^{4}$, Roberto Pistilli ${ }^{5}$, \\ Pasquale Sammartino $^{6}$, Roberta Gasparro $^{7}$ and Carlo Barausse ${ }^{1,8}$
}

Citation: Felice, P.; Bertacci, A.; Bonifazi, L.; Karaban, M.; Canullo, L.; Pistilli, R.; Sammartino, P.;

Gasparro, R.; Barausse, C. A

Proposed Protocol for Ordinary and

Extraordinary Hygienic Maintenance in Different Implant Prosthetic Scenarios. Appl. Sci. 2021, 11, 2957. https://doi.org/10.3390/app11072957

Academic Editors: Luca Testarelli,

Gilberto Sammartino and

Hom-Lay Wang

Received: 10 March 2021

Accepted: 24 March 2021

Published: 25 March 2021

Publisher's Note: MDPI stays neutral with regard to jurisdictional claims in published maps and institutional affiliations.

Copyright: (c) 2021 by the authors. Licensee MDPI, Basel, Switzerland. This article is an open access article distributed under the terms and conditions of the Creative Commons Attribution (CC BY) license (https:/ / creativecommons.org/licenses/by/ $4.0 /)$.
1 Oral Surgery, Department of Biomedical and Neuromotor Sciences, University of Bologna, 40125 Bologna, Italy; lorenzo.bonifazi@studio.unibo.it (L.B.); maryia.karaban@studio.unibo.it (M.K.); carlo.barausse2@unibo.it (C.B.)

2 Department of Biomedical and Neuromotor Sciences, School of Dentistry, University of Bologna, 40125 Bologna, Italy; angelica.bertacci3@unibo.it

3 Department of Basic Medical Sciences, Neurosciences and Sense Organs, University of Bari "Aldo Moro", 70124 Bari, Italy

4 Independent Researcher, 00198 Rome, Italy; luigicanullo@yahoo.com

5 Oral and Maxillofacial Unit, San Camillo-Forlanini Hospital, 00152 Rome, Italy; r_pistilli@libero.it

6 Private Practice, 80127 Naples, Italy; pasqualesammartino91@gmail.com

7 Department of Neuroscience, Reproductive Sciences and Dentistry, University of Naples Federico II, 80138 Naples, Italy; roberta.gasparro@unina.it

8 Postgraduate School of Oral Surgery, University of Modena and Reggio Emilia, 41124 Modena, Italy

* Correspondence: pietro.felice@unibo.it

Abstract: Prevention of peri-implantitis involves the early diagnosis of peri-implant mucositis. This article presents a protocol of hygienic maintenance in different implant prosthetic scenarios: single crown, fixed partial prosthesis, fixed full-arch, and overdentures. Others clinical conditions have to be taken into consideration: patient compliance; history of periodontitis; implants placed in augmented bone; short, zygomatic, pterygoid, and tilted implants; and complex prosthesis with false gingiva. Two levels of implant maintenance are described: ordinary, performed by dental hygienist, and extraordinary, carried out by both dentist and hygienist. Extraordinary maintenance also involves the removal and decontamination of the prosthetic structure. To obtain an effective prevention of peri-implantitis, one must plan ordinary and extraordinary hygiene in relation to the type of rehabilitation and clinical parameters.

Keywords: hygienic maintenance; innovative rehabilitative techniques; prosthetic therapy

\section{Introduction}

Dental implant placement has become a routine procedure in oral rehabilitation of fully and partially edentulous patients, involving a great variation of implant prostheses due to the development of innovative surgical and prosthetic techniques [1-5].

Inflammatory biological complications compromise the long-term results of implant therapy [6,7]. Moreover, the number of patients affected by peri-implant disease is increasing [1,8-12]. Peri-implantitis has been defined as a plaque associated pathologic condition characterized by inflammation in the peri-implant mucosa and subsequent progressive loss of supportive bone [6]. Peri-implantitis is clinically preceded by peri-implant mucositis, which is characterized by bleeding on probing and clinical signs of inflammation that can be reversed with measures aimed at eliminating the plaque $[13,14]$.

In absence of predictable treatment for peri-implantitis, primary prevention should involve the early diagnosis of peri-implant mucositis, avoiding its progression into periimplantitis [1]. Although biological complications in implant therapy cannot be completely avoided, it has been shown that proper maintenance of peri-implant tissues positively 
influences long-term success rates, while the lack of patient motivation is associated with a higher risk of peri-implantitis and implant loss $[1,15,16]$.

The purpose of this article is to propose a hygienic maintenance protocol for patients with different implant prosthesis scenarios and clinical situations.

\section{Materials and Methods}

A supportive therapy to prevent peri-implantitis should be calibrated on each single patient [17]. In clinical practice, these interventions consist of monitoring of peri-implant conditions, patient education and motivation for home oral hygiene, professional oral hygiene, and control of risk factors (e.g., history of periodontal disease).

According to the authors' clinical experience, two levels of implant maintenance can be considered: ordinary, performed by dental hygienist, and extraordinary, carried out by the dentist together with the hygienist.

The ordinary hygiene session includes soft tissue evaluation, plaque index, probing depth, bleeding on probing, presence of pus, mobility, plaque and calculus removal, and individual instructions for oral hygiene (emphasizing the use of interdental cleaning devices). Full-mouth plaque score (FMPS), full-mouth bleeding score (FMBS), periodontal probing depth (PPD), and bleeding on probing (BOP) are assessed at 6 sites using a periodontal probe [18]. Excellent motivation and compliance from patient are associated to values of FMPS $<20 \%$ and of FMBS $<20 \%$ [19]. Clinically, peri-implant health is characterized by the absence of signs of inflammation (such as edema and redness) and bleeding on probing, stability of probing depth in measurements taken at different times and absence of further bone loss compared to post-bone remodeling surgical $[13,14]$.

The scaling and root planing procedures include the use of specific instruments, such as modified curettes and piezoelectric or ultrasonic tips (in plastic material) for the removal of submucosal microbial deposits on implants and polishing with rubber cup or air polishing [20,21]. The patient should also receive personalized instructions for home oral hygiene. It is necessary to properly instruct the patient in order to respect the delicate peri-implant attachment apparatus. Given the cross-sectional differences between teeth and dental implants, using interdental brushes and other tools, such as subgingival irrigators, for interdental cleaning around dental implants allow for better plaque removal than flossing alone [22].

Extraordinary maintenance involves the removal of the prosthetic structure, operated by the dentist, to better evaluate the probing depth and the bleeding on probing, the mobility of the implants, and the state of the soft tissues, as well as to more accurately clean the implants by removing, in presence of plaque and signs of inflammation, implant abutment [23]. The same specific instruments described for the ordinary hygiene are used. Furthermore, every time the prosthesis is removed, it is decontaminated eliminating plaque and dental calculus while respecting the prosthetic surfaces. This particular machine the authors use works by gentle cleaning of the prosthesis with soft stainless-steel brushes. It helps clean and preserve dental prostheses without affecting the precision of the original design of the components. Its principle is based on soft brushes turned by powerful magnets fitted round a container which has the effect of cleaning and polishing objects (Figure 1).

To decide on an adequate maintenance choice, one must calibrate cadence and type (ordinary and extra-ordinary) in relation to the different prostheses and clinical situations.

The types of prosthetic rehabilitations have been divided into (1) single crown, (2) fixed partial prosthesis, (3) fixed full-arch, and (4) overdentures (OVD).

However, these implant prosthetic scenarios can be associated with different clinical situations, which also have to be taken into consideration: patient compliance; history of periodontitis; implants placed in augmented bone; short [24-27], zygomatic [28,29], pterygoid, and tilted implants; and complex prosthesis with false gingiva.

The results of numerous longitudinal and cross-sectional studies have provided evidence that a history of previous periodontitis (e.g., patients with previously treated pe- 
riodontitis and in supportive therapy) represents a risk factor for the development of peri-implantitis [30-32]. However, patients with a history of successfully treated periodontitis who adhere to a periodontal maintenance program are not necessarily at increased risk of developing peri-implantitis [21].
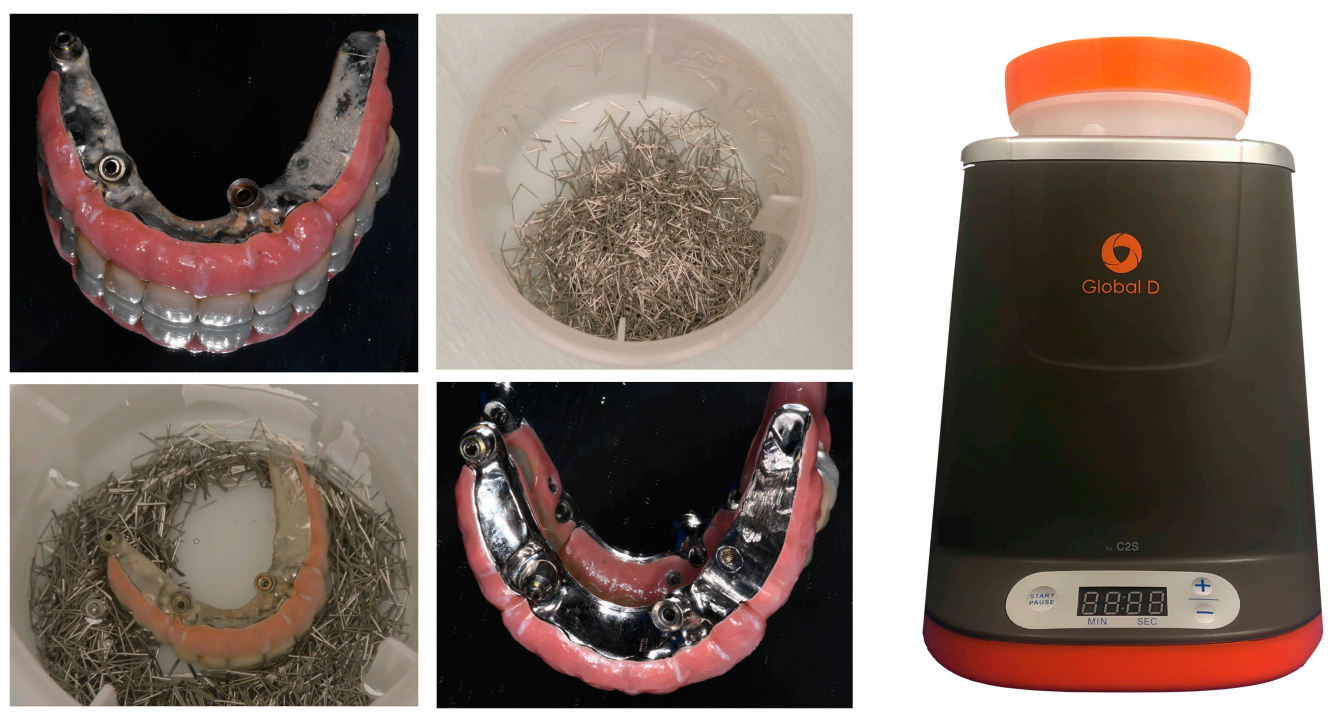

Figure 1. Example of prosthesis removed and decontaminated eliminating plaque and dental calculus while respecting the prosthetic surfaces (GD Cleaner, Global D, Brignais, France).

\section{Results and Discussion}

The present article combines authors' personal experience and literature to suggest an adequate ordinary and extraordinary hygienic maintenance protocol for different implant prosthesis scenarios and clinical conditions.

\subsection{Single Crowns}

In cases of single crowns [33-35], normally the patient can properly clean these rehabilitations. For this reason, in our opinion, ordinary hygiene should be performed every 6 months. In cases of unfavorable clinical conditions, our advice is to recall patients every 4 months. Extraordinary hygiene should be performed only in case of clinical signs of inflammation (Figure 2).

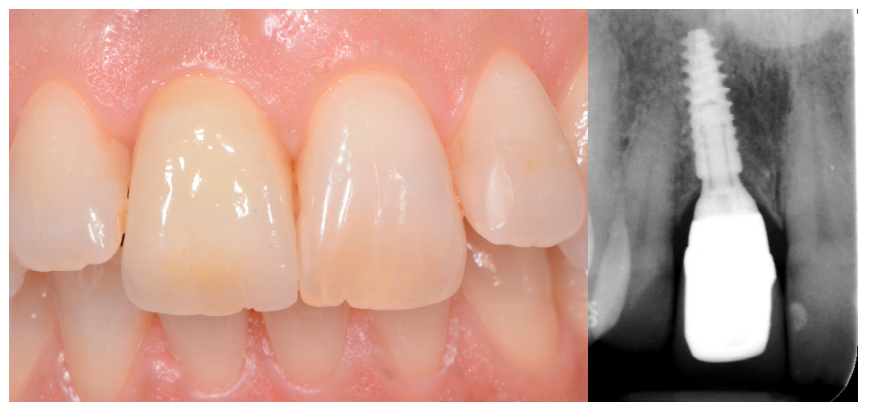

Figure 2. Single crown rehabilitation without any unfavorable clinical condition: ordinary hygiene every 6 months and extraordinary only in case of BOP+ (bleeding on probing).

\subsection{Fixed Partial Prostheses}

Fixed partial prostheses involve more than one implant, and for this reason prosthetic rehabilitations are more difficult to be cleaned by the patient. As a consequence, ordinary hygiene should be performed every 3 or 4 months on the basis of patient compliance and 
individual risk factors. Extraordinary maintenance should be repeated once a year or in cases of inflammation (Figure 3).
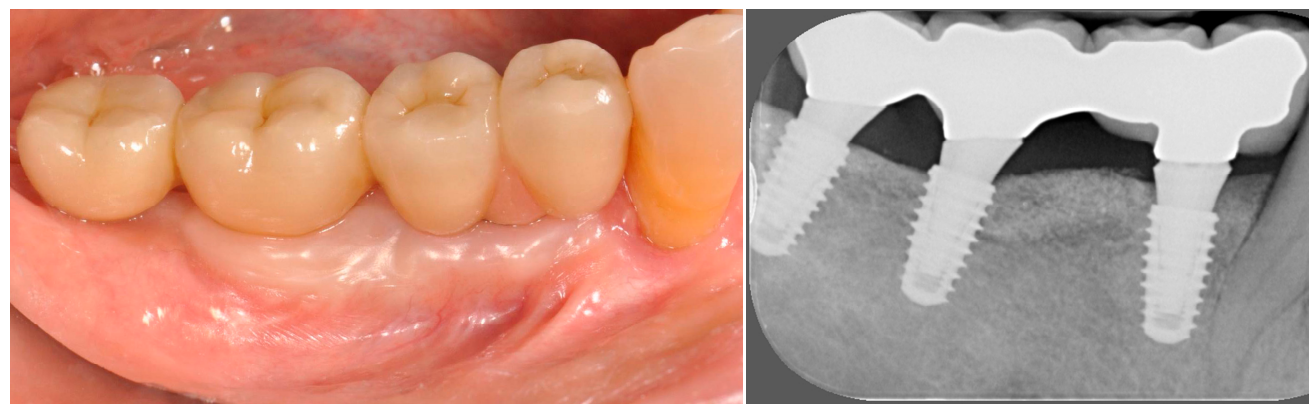

Figure 3. Fixed partial prosthesis on implants in regenerated bone: ordinary hygiene every 3 months and extraordinary every 12 months or in case of BOP+.

\subsection{Fixed Full-Arch Prostheses}

Implant-prosthetic rehabilitation type is a relevant factor, as it has been shown that, in the presence of sites difficult to access for oral hygiene maneuvers, the incidence of peri-implantitis increases [36]. In the presence of complex prosthetic rehabilitations, such as full-arch, plaque control can be challenging for the patient, even if properly trained, and an accumulation of plaque on prostheses and abutments is a frequent finding $[37,38]$. Moreover, in the presence of prostheses on several implants, the mobility of the single element can be masked, which is why it is necessary to remove the prosthesis, as well as to evaluate gingival health and hygiene conditions [39].

For these reasons, ordinary hygiene should be performed every 3 or 4 months on the basis of patient compliance and individual risk factors, while extraordinary maintenance should be repeated every 6 months (Figure 4).

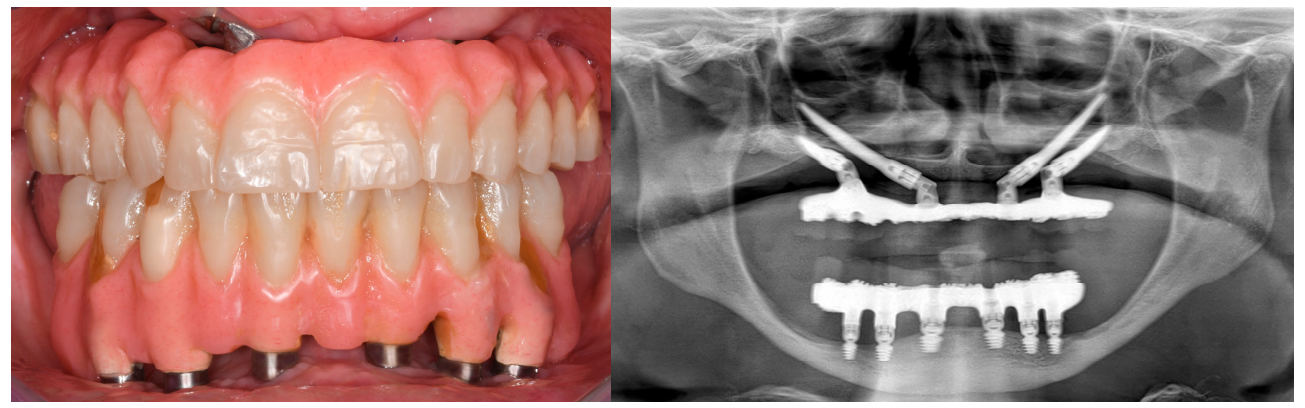

Figure 4. Fixed full-arch prosthesis on short and zygomatic implants: ordinary hygiene every 3 months and extraordinary every 6 months or in case of BOP+.

\subsection{Overdentures (OVD)}

Patients can clean at home overdenture prostheses more easily than a fixed full-arch; however, the presence of fixed prosthetic components can harbor plaque and calculus. Hence, hygiene should be performed every 3 or 4 months on the basis of the evaluation of clinical parameters and patient compliance. Extraordinary maintenance should be performed only in presence of clinical signs of inflammation (Figure 5).

Other important and specific clinical factors have to be taken into consideration. For instance, the prevalence of peri-implantitis in patients with implants in augmented sites is more variable and less predictable compared with the prevalence in patients with implants in pristine sites [40-44]. There are differences in bone loss during the spontaneous progression period between pristine and augmented: the size and vertical dimension of the peri-implantitis lesion were larger at augmented than at pristine sites and the findings 
seemed to be confirmed by clinical data, which showed a faster and worsening progression of peri-implantitis in augmented bone [45].
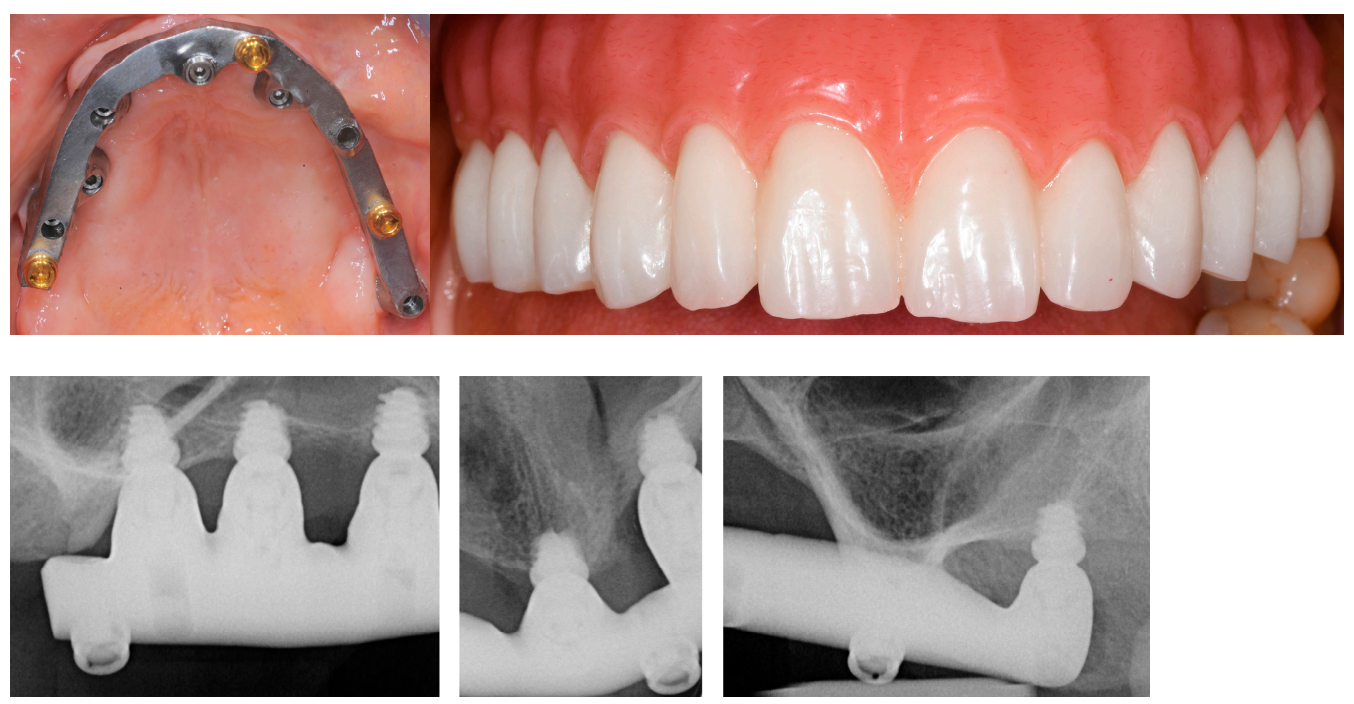

Figure 5. Overdenture (OVD) prosthesis on short implants: ordinary hygiene every 3 months and extraordinary only in case of $\mathrm{BOP}+$.

In patients with severely atrophic maxillae, zygomatic implants represent an alternative to conventional bone augmentation with the advantage of a fast functional rehabilitation $[27,28]$. However, according to the literature, this kind of prosthetic rehabilitation is associated with an increased risk of mucositis [28]. The presence of false prosthetic gingiva, often related to zygomatic, tilted, and pterygoid implants, can favor plaque accumulation and retention.

Nowadays short implants (defined as $\leq 6 \mathrm{~mm}$ long) are used as an alternative to reconstructive bone surgeries due to their up-to-date reliable results [26,27,46-48]. Despite of stable peri-implant marginal bone levels, short implants require a special attention in order to avoid marginal bone loss.

For all of these patients with unfavorable clinical conditions, ordinary hygiene should be performed every 4 months for single crowns and every 3 months in all the other rehabilitations (Table 1, Figure 6). Especially in these kinds of rehabilitations, special attention should be given to the extraordinary hygiene removing the prosthesis and using the extra-oral magnetic cleaner.

Table 1. Ordinary and extraordinary hygienic maintenance in different implant prosthetic scenarios.

\begin{tabular}{ccc}
\hline $\begin{array}{c}\text { Types of Implant Prosthetic } \\
\text { Rehabilitations }\end{array}$ & $\begin{array}{c}\text { ORDINARY } \\
\text { Hygiene (Months) }\end{array}$ & $\begin{array}{c}\text { EXTRAORDINARY } \\
\text { Hygiene (Months) }\end{array}$ \\
\hline Single crown & $6 / 4^{*}$ & BOP+ \\
\hline Fixed partial prosthesis & $4 / 3^{*}$ & $12 / \mathrm{BOP}+$ \\
\hline Fixed full-arch & $4 / 3^{*}$ & $6 / \mathrm{BOP}+$ \\
\hline Overdentures & $4 / 3^{*}$ & $\mathrm{BOP}+$ \\
\hline
\end{tabular}

* Patient compliance ${ }^{*}$ history of periodontitis ${ }^{*}$ augmented bone ${ }^{*}$ short implants $(\leq 6 \mathrm{~mm} \mathrm{long}){ }^{*} \mathrm{zygo}-$ matic/pterygoid/tilted implants * complex prosthesis with false gingiva. BOP: bleeding on probing.

However, all the limitations of a communication should be taken into consideration: the lack of a control group and of a sample size calculation, and the absence of a statistical analysis and of a rigorous study design. For this reason, we strongly suggest for future research studies to confirm these results. 


\section{Hygienic maintenance}

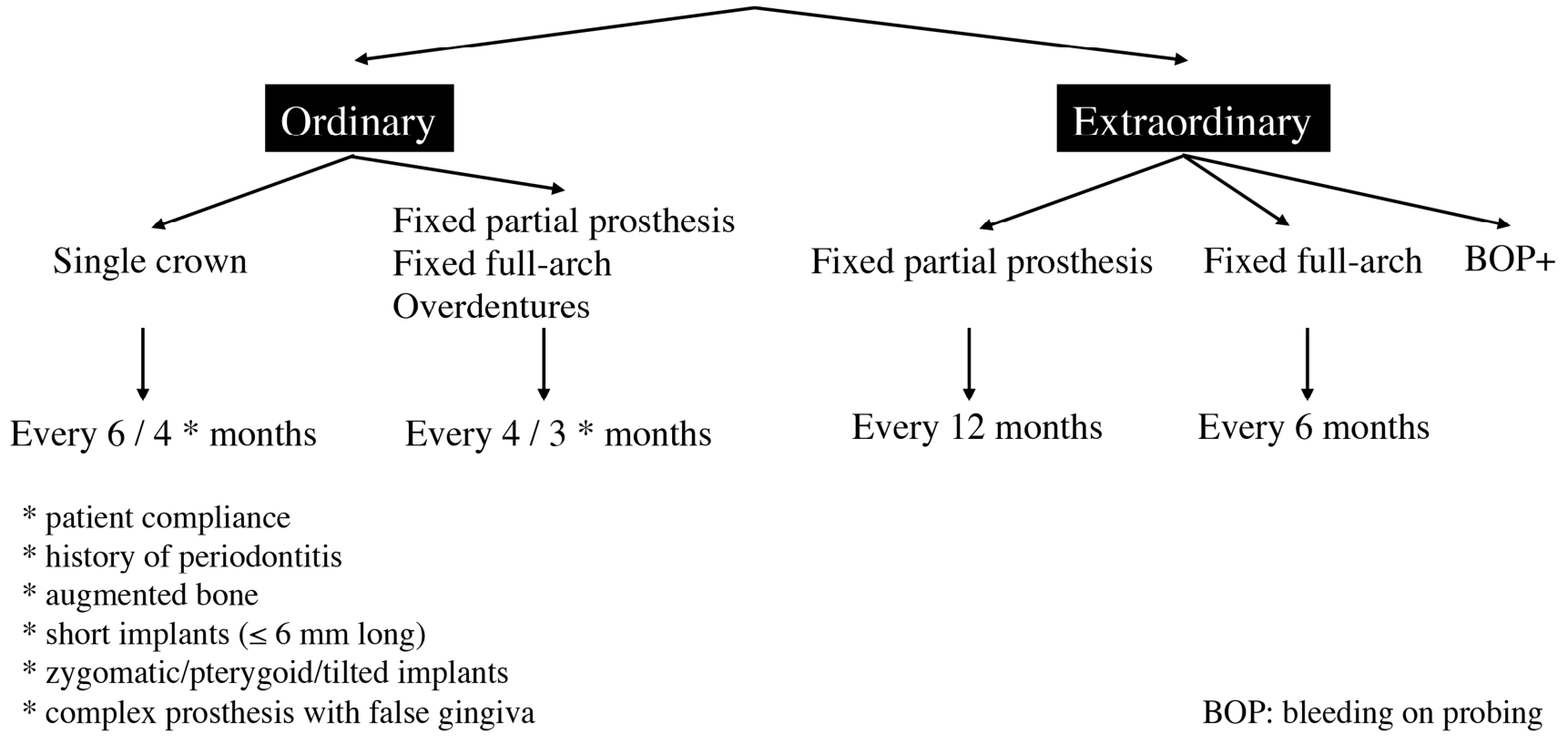

Figure 6. Ordinary and extraordinary hygienic maintenance in different implant prosthetic scenarios.

\section{Conclusions}

Within all the limitations of an article mainly based on clinical experience, we have proposed a proper maintenance hygienic protocol in order to prevent peri-implantitis. Ordinary hygiene sessions should be performed by a dental hygienist every 6 months in cases of single crowns and every 4 months in all the other prosthetic rehabilitations. In cases of unfavorable clinical conditions (reduced patient compliance; history of periodontitis; implants placed in augmented bone; short, zygomatic, pterygoid, and tilted implants; complex prosthesis with false gingiva), ordinary hygiene should be performed more frequently (every 4 months for the single crowns and every 3 months in all other cases). Regarding extraordinary hygiene, performed by both dentist and hygienist, it should be done by removing prosthesis in any case of inflammation, and every 6 and 12 months for fixed full-arch and partial prostheses, respectively. However, randomized controlled clinical trials (RCTs) should be performed to better confirm these clinical opinions.

Author Contributions: Conceptualization, P.F. and C.B.; methodology, L.C.; validation, R.G; writingoriginal draft preparation, A.B., L.B., and M.K.; writing-review and editing, R.G. and P.S.; visualization, P.S.; supervision, R.P. All authors have read and agreed to the published version of the manuscript.

Funding: This research received no external funding.

Institutional Review Board Statement: Not applicable since it is a communication reporting authors' clinical experience on routinary hygienic protocols. No research clinical treatments on these protocols were delivered.

Informed Consent Statement: Patient's figures were completely anonymized so a formal consent to show images was not elaborated.

Data Availability Statement: Not applicable.

Conflicts of Interest: Prof. Felice receives research grants from Global D. 


\section{References}

1. Jepsen, S.; Berglundh, T.; Genco, R.; Aass, A.M.; Demirel, K.; Derks, J.; Figuero, E.; Giovannoli, J.L.; Goldstein, M.; Lambert, F.; et al. Primary prevention of peri-implantitis: Managing peri-implant mucositis. J. Clin. Periodontol. 2015, 42, S152-S157. [CrossRef] [PubMed]

2. Menini, M.; Setti, P.; Pera, P.; Pera, F.; Pesce, P. Peri-implant Tissue Health and Bone Resorption in Patients with Immediately Loaded, Implant-Supported, Full-Arch Prostheses. Int. J. Prosthodont. 2018, 31, 327-333. [CrossRef]

3. Crespi, R.; Capparé, P.; Crespi, G.; Lo Giudice, G.; Gastaldi, G.; Gherlone, E. Immediate Implant Placement in Sockets with Asymptomatic Apical Periodontitis. Clin. Implant. Dent. Relat. Res. 2017, 19, 20-27. [CrossRef]

4. Tribst, J.P.M.; Dal Piva, A.M.O.; Lo Giudice, R.; Borges, A.L.S.; Bottino, M.A.; Epifania, E.; Ausiello, P. The Influence of CustomMilled Framework Design for an Implant-Supported Full-Arch Fixed Dental Prosthesis: 3D-FEA Sudy. Int. J. Environ. Res. Public Health 2020, 17, 4040. [CrossRef]

5. Troiano, A.; Lo Giudice, G.; De Luca, R.; Lo Giudice, F.; D'Amato, S.; Tartaro, G.; Colella, G. Salvage of Dental Implant Located in Mandibular Odontogenic Cyst. A Conservative Surgical Treatment Proposal. Dent. J. 2020, 8, 49. [CrossRef] [PubMed]

6. Schwarz, F.; Derks, J.; Monje, A.; Wang, H.L. Peri-implantitis. J. Clin. Periodontol. 2018, 45, S246-S266. [CrossRef]

7. Matarese, G.; Ramaglia, L.; Fiorillo, L.; Cervino, G.; Lauritano, F.; Isola, G. Implantology and Periodontal Disease: The Panacea to Problem Solving? Open Dent. J. 2017, 11, 460-465. [CrossRef]

8. Di Gianfilippo, R.; Sirinirund, B.; Rodriguez, M.V.; Chen, Z.; Wang, H.-L. Long-Term Prognosis of Peri-Implantitis Treatment: A Systematic Review of Prospective Trials with More Than 3 Years of Follow-Up. Appl. Sci. 2020, 10, 17. [CrossRef]

9. Pesce, P.; Canullo, L.; Grusovin, M.G.; de Bruyn, H.; Cosyn, J.; Pera, P. Systematic review of some prosthetic risk factors for periimplantitis. J. Prosthet. Dent. 2015, 114, 346-350. [CrossRef] [PubMed]

10. Turri, A.; Rossetti, P.H.; Canullo, L.; Grusovin, M.G.; Dahlin, C. Prevalence of Peri-implantitis in Medically Compromised Patients and Smokers: A Systematic Review. Int. J. Oral Maxillofac. Implants 2016, 31, 111-118. [CrossRef] [PubMed]

11. Rakic, M.; Galindo-Moreno, P.; Monje, A.; Radovanovic, S.; Wang, H.L.; Cochran, D.; Sculean, A.; Canullo, L. How frequent does peri-implantitis occur? A systematic review and meta-analysis. Clin. Oral Investig. 2018, 22, 1805-1816. [CrossRef] [PubMed]

12. Tallarico, M.; Canullo, L.; Wang, H.L.; Cochran, D.L.; Meloni, S.M. Classification Systems for Peri-implantitis: A Narrative Review with a Proposal of a New Evidence-Based Etiology Codification. Int. J. Oral Maxillofac. Implants 2018, 33, 871-879. [CrossRef]

13. Berglundh, T.; Armitage, G.; Araujo, M.G.; Avila-Ortiz, G.; Blanco, J.; Camargo, P.M.; Chen, S.; Cochran, D.; Derks, J.; Figuero, E.; et al. Peri-implant diseases and conditions: Consensus report of workgroup 4 of the 2017 World Workshop on the Classification of Periodontal and Peri-Implant Diseases and Conditions. J. Clin. Periodontol. 2018, 45, S286-S291. [CrossRef]

14. Caton, J.G.; Armitage, G.; Berglundh, T.; Chapple, I.L.C.; Jepsen, S.; Kornman, K.S.; Mealey, B.L.; Papapanou, P.N.; Sanz, M.; Tonetti, M.S. A new classification scheme for periodontal and peri-implant diseases and conditions - Introduction and key changes from the 1999 classification. J. Clin. Periodontol. 2018, 45, S1-S8. [CrossRef]

15. Schwarz, F.; Becker, K.; Sager, M. Efficacy of professionally administered plaque removal with or without adjunctive measures for the treatment of peri-implant mucositis: A systematic review and meta-analysis. J. Clin. Periodontol. 2015, 42, S202-S213. [CrossRef] [PubMed]

16. Roccuzzo, M.; Bonino, L.; Dalmasso, P.; Aglietta, M. Long-term results of a three arms prospective cohort study on implants in periodontally compromised patients: 10-year data around sandblasted and acid-etched (SLA) surface. Clin. Oral Implants Res. 2014, 25, 1105-1112. [CrossRef]

17. Tonetti, M.S.; Chapple, I.L.; Jepsen, S.; Sanz, M. Primary and secondary prevention of periodontal and peri-implant diseases: Introduction to, and objectives of the 11th European Workshop on Periodontology consensus conference. J. Clin. Periodontol. 2015, 42, S1-S4. [CrossRef]

18. Guarnieri, R.; Di Nardo, D.; Di Giorgio, G.; Miccoli, G.; Testarelli, L. Longevity of Teeth and Dental Implants in Patients Treated for Chronic Periodontitis Following Periodontal Maintenance Therapy in a Private Specialist Practice: A Retrospective Study with a 10-Year Follow-up. Int. J. Periodontics Restor. Dent. 2021, 41, 89-98. [CrossRef] [PubMed]

19. Roccuzzo, M.; Grasso, G.; Dalmasso, P. Keratinized mucosa around implants in partially edentulous posterior mandible: 10-year results of a prospective comparative study. Clin. Oral Implants Res. 2016, 27, 491-496. [CrossRef]

20. Blasi, A.; Iorio-Siciliano, V.; Pacenza, C.; Pomingi, F.; Matarasso, S.; Rasperini, G. Biofilm removal from implants supported restoration using different instruments: A 6-month comparative multicenter clinical study. Clin. Oral Implants Res. 2016, 27, e68-e73. [CrossRef]

21. Armitage, G.C.; Xenoudi, P. Post-treatment supportive care for the natural dentition and dental implants. Periodontol. 2000 2016, 71, 164-184. [CrossRef] [PubMed]

22. Geisinger, M.L.; Ogdon, D.; Kaur, M.; Valiquette, G.; Geurs, N.C.; Reddy, M.S. Toss the Floss? Evidence-Based Oral Hygiene Recommendations for the Periodontal Patient in the Age of "Flossgate". Clin. Adv. Periodontics 2019, 9, 83-90. [CrossRef]

23. Bidra, A.S.; Daubert, D.M.; Garcia, L.T.; Kosinski, T.F.; Nenn, C.A.; Olsen, J.A.; Platt, J.A.; Wingrove, S.S.; Chandler, N.D.; Curtis, D.A. Clinical Practice Guidelines for Recall and Maintenance of Patients with Tooth-Borne and Implant-Borne Dental Restorations. J. Prosthodont. 2016, 25, S32-S40. [CrossRef]

24. Felice, P.; Barausse, C.; Pistilli, R.; Ippolito, D.R.; Esposito, M. Short implants versus longer implants in vertically augmented posterior mandibles: Result at 8 years after loading from a randomised controlled trial. Eur. J. Oral Implantol. 2018, 11, 385-395. 
25. Esposito, M.; Buti, J.; Barausse, C.; Gasparro, R.; Sammartino, G.; Felice, P. Short implants versus longer implants in vertically augmented atrophic mandibles: A systematic review of randomised controlled trials with a 5-year post-loading follow-up. Int. J. Oral Implantol. 2019, 12, 267-280.

26. Esposito, M.; Zucchelli, G.; Barausse, C.; Pistilli, R.; Trullenque-Eriksson, A.; Felice, P. Four mm-long versus longer implants in augmented bone in atrophic posterior jaws: 4-month post-loading results from a multicentre randomised controlled trial. Eur. J. Oral Implantol. 2016, 9, 393-409. [PubMed]

27. Esposito, M.; Barausse, C.; Pistilli, R.; Checchi, V.; Diazzi, M.; Gatto, M.R.; Felice, P. Posterior jaws rehabilitated with partial prostheses supported by $4.0 \times 4.0 \mathrm{~mm}$ or by longer implants: Four-month post-loading data from a randomised controlled trial. Eur. J. Oral Implantol. 2015, 8, 221-230.

28. Davó, R.; Felice, P.; Pistilli, R.; Barausse, C.; Marti-Pages, C.; Ferrer-Fuertes, A.; Ippolito, D.R.; Esposito, M. Immediately loaded zygomatic implants vs. conventional dental implants in augmented atrophic maxillae: 1-year post-loading results from a multicentre randomised controlled trial. Eur. J. Oral Implantol. 2018, 11, 145-161. [PubMed]

29. Esposito, M.; Davó, R.; Marti-Pages, C.; Ferrer-Fuertes, A.; Barausse, C.; Pistilli, R.; Ippolito, D.R.; Felice, P. Immediately loaded zygomatic implants vs. conventional dental implants in augmented atrophic maxillae: 4 months post-loading results from a multicentre randomised controlled trial. Eur. J. Oral Implantol. 2018, 11, 11-28.

30. Roccuzzo, M.; De Angelis, N.; Bonino, L.; Aglietta, M. Ten-year results of a three-arm prospective cohort study on implants in periodontally compromised patients. Part 1: Implant loss and radiographic bone loss. Clin. Oral Implants Res. 2010, 21, 490-496. [CrossRef]

31. Roccuzzo, M.; Bonino, F.; Aglietta, M.; Dalmasso, P. Ten-year results of a three arms prospective cohort study on implants in periodontally compromised patients. Part 2: Clinical results. Clin. Oral Implants Res. 2012, 23, 389-395. [CrossRef]

32. Derks, J.; Schaller, D.; Håkansson, J.; Wennström, J.L.; Tomasi, C.; Berglundh, T. Effectiveness of Implant Therapy Analyzed in a Swedish Population: Prevalence of Peri-implantitis. J. Dent. Res. 2016, 95, 43-49. [CrossRef] [PubMed]

33. Felice, P.; Zucchelli, G.; Cannizzaro, G.; Barausse, C.; Diazzi, M.; Trullenque-Eriksson, A.; Esposito, M. Immediate, immediatedelayed ( 6 weeks) and delayed (4 months) post-extractive single implants: 4-month post-loading data from a randomised controlled trial. Eur. J. Oral Implantol. 2016, 9, 233-247. [PubMed]

34. Esposito, M.; Zucchelli, G.; Cannizzaro, G.; Checchi, L.; Barausse, C.; Trullenque-Eriksson, A.; Felice, P. Immediate, immediatedelayed ( 6 weeks) and delayed (4 months) post-extractive single implants: 1-year post-loading data from a randomised controlled trial. Eur. J. Oral Implantol. 2017, 10, 11-26. [PubMed]

35. De Angelis, N.; Felice, P.; Pellegrino, G.; Camurati, A.; Gambino, P.; Esposito, M. Guided bone regeneration with and without a bone substitute at single post-extractive implants: 1-year post-loading results from a pragmatic multicentre randomised controlled trial. Eur. J. Oral Implantol. 2011, 4, 313-325.

36. Serino, G.; Ström, C. Peri-implantitis in partially edentulous patients: Association with inadequate plaque control. Clin. Oral Implants Res. 2009, 20, 169-174. [CrossRef]

37. Esposito, M.; Felice, P.; Barausse, C.; Pistilli, R.; Grandi, G.; Simion, M. Immediately loaded machined versus rough surface dental implants in edentulous jaws: One-year postloading results of a pilot randomised controlled trial. Eur. J. Oral Implantol. 2015, 8 , 387-396.

38. Cannizzaro, G.; Felice, P.; Gherlone, E.; Barausse, C.; Ferri, V.; Leone, M.; Trullenque-Eriksson, A.; Esposito, M. Immediate loading of two (fixed-on-2) vs. four (fixed-on-4) implants placed with a flapless technique supporting mandibular cross-arch fixed prostheses: 3-year results from a pilot randomised controlled trial. Eur. J. Oral Implantol. 2017, 10, 133-145. [PubMed]

39. Humphrey, S. Implant maintenance. Dent. Clin. N. Am. 2006, 50, 463-478. [CrossRef]

40. Heitz-Mayfield, L.J.; Aaboe, M.; Araujo, M.; Carrión, J.B.; Cavalcanti, R.; Cionca, N.; Cochran, D.; Darby, I.; Funakoshi, E.; Gierthmuehlen, P.C.; et al. Group 4 ITI Consensus Report: Risks and biologic complications associated with implant dentistry. Clin. Oral Implants Res. 2018, 29, 351-358. [CrossRef]

41. Esposito, M.; Cannizzaro, G.; Barausse, C.; Cosci, F.; Soardi, E.; Felice, P. Cosci versus Summers technique for crestal sinus lift: 3-year results from a randomised controlled trial. Eur. J. Oral Implantol. 2014, 7, 129-137.

42. Felice, P.; Pistilli, R.; Zucchelli, G.; Simion, M.; Karaban, M.; Bonifazi, L.; Barausse, C. Decision Criteria Proposed for the Treatment of Vertical Bone Atrophies in the Posterior Mandible. Int. J. Periodontics Restor. Dent. 2021, 41, 71-77. [CrossRef]

43. Checchi, V.; Felice, P.; Zucchelli, G.; Barausse, C.; Piattelli, M.; Pistilli, R.; Grandi, G.; Esposito, M. Wide diameter immediate post-extractive implants vs. delayed placement of normal-diameter implants in preserved sockets in the molar region: 1-year post-loading outcome of a randomised controlled trial. Eur. J. Oral Implantol. 2017, 10, 263-278. [PubMed]

44. Felice, P.; Barausse, C.; Barone, A.; Zucchelli, G.; Piattelli, M.; Pistilli, R.; Ippolito, D.R.; Simion, M. Interpositional Augmentation Technique in the Treatment of Posterior Mandibular Atrophies: A Retrospective Study Comparing 129 Autogenous and Heterologous Bone Blocks with 2 to 7 Years Follow-Up. Int. J. Periodontics Restor. Dent. 2017, 37, 469-480. [CrossRef] [PubMed]

45. Carcuac, O.; Abrahamsson, I.; Derks, J.; Petzold, M.; Berglundh, T. Spontaneous progression of experimental peri-implantitis in augmented and pristine bone: A pre-clinical in vivo study. Clin. Oral Implants Res. 2020, 31, 192-200. [CrossRef]

46. Felice, P.; Pistilli, R.; Barausse, C.; Piattelli, M.; Buti, J.; Esposito, M. Posterior atrophic jaws rehabilitated with prostheses supported by 6-mm-long 4-mm-wide implants or by longer implants in augmented bone. Five-year post-loading results from a within-person randomised controlled trial. Int. J. Oral Implantol. 2019, 12, 57-72. 
47. Esposito, M.; Barausse, C.; Pistilli, R.; Piattelli, M.; Di Simone, S.; Ippolito, D.R.; Felice, P. Posterior atrophic jaws rehabilitated with prostheses supported by $5 \times 5 \mathrm{~mm}$ implants with a nanostructured calcium-incorporated titanium surface or by longer implants in augmented bone. Five-year results from a randomised controlled trial. Int. J. Oral Implantol. 2019, 12, 39-54.

48. Felice, P.; Barausse, C.; Pistilli, R.; Ippolito, D.R.; Esposito, M. Five-year results from a randomised controlled trial comparing prostheses supported by 5 -mm long implants or by longer implants in augmented bone in posterior atrophic edentulous jaws. Int. J. Oral Implantol. 2019, 12, 25-37. 